\title{
Modelagem Matemática no ensino de Matemática para engenharia
}

Elaine Cristina Ferruzzi

Lourdes Maria Werle de Almeida

\begin{abstract}
Resumo
Este artigo apresenta um estudo sobre a utilização da Modelagem Matemática em sala de aula de engenharia como uma forma de contribuir para o desenvolvimento matemático, pessoal e social do futuro engenheiro. Com bases em dados observados em sala de aula durante o desenvolvimento de algumas atividades podemos inferir que mesmo em um curso regular, com limitações de tempo e conteúdos, é possível desenvolver atividades de Modelagem e proporcionar o desenvolvimento de conteúdos matemáticos, bem como atitudes de investigação, resolução de problemas e habilidades sociais do futuro engenheiro.
\end{abstract}

Palavras-chave: modelagem matemática, ensino de engenharia, educação matemática.

\begin{abstract}
This article presents a study on the use of mathematical modeling in the classroom engineering as a way to contribute to the mathematical development personal and social engineers of the future. With bases on observed data in the classroom during the development of some activities we can infer thar even in a regular course, with time constraints and content, it is possible to develop modeling activities and provide the development of mathematical content as well as attitudes research, problem solving and social skill of the future engineer.

Keywords: mathematical modeling, engineering education, mathematicaleducation.
\end{abstract}




\section{Introdução}

As descobertas tecnológicas, os avanços na área da comunicação, genética, entre outras que vem ocorrendo nas últimas décadas tem provocado transformações significativas em várias áreas do conhecimento, entre elas a exigência profissional e as relações pessoais. Estas mudanças conduzem a novos contornos educacionais e o ensino de engenharia se insere neste contexto de inovações.

De acordo com Vallim, Farines e Cury (2006), as mudanças de base tecnológicas, divisões de trabalho e a globalização da economia, colocam engenheiros frente a situações nas quais devem solucionar problemas cada vez mais estruturados e complexos, em um ambiente em constante mudança. Porém, tem-se observado que, ao deparar-se com um problema real a ser solucionado, dificilmente o indivíduo consegue realizar uma conexão entre o que estudou e o problema a ser solucionado, nas palavras destes autores (2006, p.1),

“...uma das dificuldades é, diante de uma situação real, perceber a oportunidade para aplicar um conceito teórico. Outra é fazer as adaptações necessárias para que um problema real possa ser tratado por algum conhecimento teórico pertinente".

Esta afirmação vai ao encontro do entendimento de Coll (1994) quando afirma que se por um lado a quantidade de informações que se transmite ao aluno é cada vez maior, por outro lado, a capacidade de utilizar estas informações encontra-se em diminuição significativa. Neste sentido, o que se almeja é a formação de profissionais capazes de formular e resolver problemas, modelar situações e analisar de forma crítica os resultados obtidos.

A capacidade de solucionar problemas e modelar situações constitui uma das atribuições do ensino de matemática, deste modo, a exigência atribuída ao profissional da área de engenharia faz com que a Matemática extrapole seus próprios limites disciplinares, buscando realizar conexões com a realidade, na busca por experiências que conduzam o estudante a deparar-se com situações problemas que necessitem de solução.

Além destas "qualidades" exigidas do profissional da engenharia, Vallim, Farines e Cury (2006) afirmam que a atual tendência do mundo do trabalho intensifica a exigência para este profissional, esperando que sua formação "reflita equilíbrio entre competências técnicas sofisticadas e habilidades intra e interpessoais, incluindo comunicação, trabalho em equipe, gerenciamento, criatividade, responsabilidade social, sensibilidade para ética e desenvolvimento sustentável". Para Coll (1994, p. 100) esta mudança de perspectiva trouxe para o campo educativo a evidência "do inadequado de alguns métodos de ensino essencialmente expositivos que concebem o professor $e$ o aluno como simples transmissor $e$ receptor de conhecimentos". Neste sentido, as atividades desenvolvidas em sala de aula devem propiciar 
problemas que devem ser solucionados pelos alunos conduzindo-os a utilizar seus conhecimentos e buscar a aprendizagem de outros desconhecidos.

Diante disto temos observado crescente preocupação com o ensino da matemática para os estudantes de engenharia com vistas a minimizar este distanciamento entre o conhecimento teórico e aplicações deste conhecimento em sua prática profissional, além da preocupação com aspectos de sua formação geral, como a comunicação e a cooperação.

Neste artigo apresentamos a Modelagem Matemática em sala de aula como uma possibilidade de desenvolver a matemática essencial para o engenheiro bem como a possibilidade de desenvolver algumas atitudes exigidas para este profissional.

\section{Ensino de matemática na engenharia}

É consenso que a Matemática é imprescindível para a educação do engenheiro e que ensino da matemática nos cursos de engenharia deve ir além da resolução de exercícios rotineiros e aplicação de fórmulas. Para Pinheiro e Moretti (2003, p.7) o principal papel da matemática nestes cursos é prover os alunos

"de subsídios que os permita interpretar os dados, analisar os modelos propostos, de forma que possam melhor representar a realidade, adquirindo ferramentas que thes possibilite a resolução de problemas".

Os mesmos autores ainda afirmam que não é suficiente que os futuros engenheiros conheçam o cálculo necessário como ferramenta para sua atuação profissional,

É preciso que eles próprios possam construir novos modelos para entender a realidade, discutindo as suas influências e posicionando-se face aos tópicos abordados, (...) tomando decisões fundamentadas nas suas reflexões em favor do contexto social (PINHEIRO E MORETTI, 2003, p.10).

A competência para analise e reflexão citada por Pinheiro e Moretti (2003) tem se mostrado extremamente exigida dos profissionais, visto que, muitas decisões são tomadas com base em dados estatísticos e modelos matemáticos.

Por outro lado, é consenso também que a Matemática tem sido uma das principais responsáveis pela reprovação e/ou desistência de estudantes, sendo que

"(...)a insatisfação de alunos e professores sobre os resultados escolares nessa ciência, indica que existem problemas sobre sua prática de ensino $e$ aprendizagem que precisam ser encarados (BATHELT e CEOLIN, 2001").

Geralmente, no ensino da Matemática o professor apresenta conteúdos estruturados e prontos, limpos de possibilidades de erros. Estes conteúdos apresentam-se em sua forma final e,

R. B. E. C. T., vol 6, núm. 1, jan-abr.2013 ISSN - 1982-873X 
sendo assim, não cabe nesta "transmissão de conteúdos" abertura para discussões e opiniões . Cabe ao aluno a função única de estar atento e "captar" os conteúdos apresentados pelo docente. Tem-se assim, uma cultura de que, se o aluno não aprende desta maneira, deve ser por causa da falta de atenção dele e não por responsabilidade do professor.

Ainda constata-se que disciplinas de matemática geralmente são tratadas, por alguns professores, de forma independente das disciplinas específicas da área tecnológica, provocando assim, falta de conhecimento sobre as aplicações da Matemática. Estas disciplinas possuem a característica da ênfase ser dada nas técnicas, minimizando a reflexão acerca dos conceitos e das aplicações da Matemática. Isto acarreta uma das indagações geralmente feitas pelos alunos sobre a aplicabilidade dos conteúdos matemáticos estudados.

Além disso, as bibliografias utilizadas pelos professores de Matemática raramente trazem aplicações voltadas à área específica de Engenharia. Neste sentido Biembengut (1997, p.11) salienta que

“(...) a ausência de tópicos aplicados à área específica, nos livros de matemática, traz dificuldades àquele que ensina e àquele que deveria aprender, para uma melhor compreensão prática daquilo que está sendo exposto".

A falta de vivência nestas aplicações tem mostrado ao longo do tempo a dificuldade dos alunos na compreensão e aplicação dos conteúdos teóricos matemáticos em seu campo profissional e na sua vida diária.

A memorização de conceitos matemáticos não garante o reconhecimento de uma situação problema e da aplicação dos conceitos necessários para solucioná-la. É importante desenvolver com os alunos aplicações de conceitos matemáticos em situações do dia-a-dia, e mais do que isso, é preciso que os estudantes desenvolvam a capacidade de refletir acerca dos resultados destas aplicações. Deste modo, entende-se que o isolamento do ensino da matemática deve ser investigado e solucionado.

A possibilidade de romper com este isolamento é uma expectativa cada vez mais almejada pelos educadores e sociedade em geral. Embora o uso da Matemática em muitas situações reais seja quase um consenso entre os matemáticos, ainda existem lacunas no que se refere ao ensino da Matemática escolar. $O$ insucesso de alguns alunos é frequentemente atribuído a numerosos fatores, entre os quais se destacam os métodos pedagógicos inadequados que reduzem a motivação dos alunos e em pouco contribuem para a aprendizagem.

Neste sentido o professor dever auxiliar o processo de construção de conhecimento do aluno, levando-o a participar de tarefas que possibilitem a aprendizagem da matemática e ainda auxiliem na sua formação geral. Blum (1991) considera que a conexão entre a vida real e a Matemática origina matéria de reflexão, levando a consciência do papel da Matemática na 
sociedade. Assim, enfatiza a preparação para a vida real, como pessoas atuantes na sociedade, com habilidades para formar juízos próprios, reconhecer e compreender exemplos de aplicação de conceitos matemáticos.

Deste modo, entende-se ser importante conceber a Matemática como uma ciência que pode ser praticada, vivenciando-a de forma que alguns problemas que surjam do cotidiano do estudante possam ser trabalhados em sala de aula, possibilitando a exploração e construção dos conceitos matemáticos por meio de atividades que tenham significado para o aluno, buscando assim a construção do seu conhecimento.

Este cenário nos conduzir a investigar alternativas pedagógicas com vistas a colaborar com esta educação matemática para o engenheiro. Uma das alternativas pedagógicas que proporcionam atividades em grupo, oportunidades de solucionar problemas, construção de modelos e aproximação da realidade do estudante à matemática teórica tem sido a Modelagem Matemática em sala de aula.

\section{Modelagem Matemática na educação}

Em nossa pesquisa entendemos Modelagem Matemática como a

"busca de uma representação matemática para um objeto ou um fenômeno, que pode ser matemático ou não. Neste sentido, trata-se de um procedimento criativo e interpretativo que estabelece uma estrutura matemática que deve incorporar as características essenciais do objeto ou fenômeno que pretende representar (ALMEIDA e FERRUZZI, 2009, p. 120)".

Considerando que a construção desta representação pode ocorrer em sala de aula, diversos focos de pesquisa têm sido evidenciados: a relação entre conhecimentos matemáticos e extra-matemáticos; critérios para avaliação da utilização da Modelagem em sala de aula; envolvimento dos personagens; uso das tecnologias de comunicação e informação em atividades entre outros.

Neste sentido, muitos educadores da área de Educação Matemática têm apresentado argumentos favoráveis à sua introdução em sala de aula. Esta introdução tem sido pontuada sob diferentes justificativas, levando em consideração: a reflexão dos alunos sobre o papel da Matemática na sociedade; a aprendizagem de conceitos matemáticos; a oportunidade de exercer um papel investigativo; a motivação; o desenvolvimento da capacidade de solucionar problemas entre outras.

No encaminhamento dado às atividades de Modelagem em sala de aula, os envolvidos realizam um conjunto de ações, como a compreensão da situação-problema, busca por informações sobre o fenômeno, identificação e seleção de variáveis, elaboração de hipóteses,

R. B. E. C. T., vol 6, núm. 1, jan-abr.2013 ISSN - 1982-873X 
simplificação do problema, obtenção e validação de um modelo matemático, e a comunicação dos resultados. Observa-se que estas ações estão em consonância com a educação almejada aos futuros engenheiros.

A escolha pelo desenvolvimento de atividades de Modelagem Matemática no ensino da matemática deu-se pelos diversos argumentos ${ }^{1}$ encontrados na literatura a favor da sua inserção em sala de aula. Entre os argumentos encontrados na literatura alguns vão ao encontro da expectativa da educação de um engenheiro: i)proporcionam atividades em grupo que favorecem a comunicação, respeito, capacidade de trabalhar em equipe e liderança; ii) oportunidades para solucionar problemas e construir modelos com base em hipóteses; iii) aproxima a realidade do estudante à matemática teórica, entre outros.

Além destas "qualidades" importantes para o engenheiro, quando trabalhamos com Modelagem em sala de aula temos, obviamente, o objetivo de ensinar matemática, e o desenvolvimento destas atividades tem proporcionado aos alunos vivenciar a matemática presente em situações que podem ser encontradas em sua atividade profissional, fato este que parece contribuir para seu engajamento na atividade e consequentemente na procura por conceitos matemáticos não apreendidos ainda.

Com o objetivo de contribuir para a educação matemática e educação geral de nossos estudantes temos desenvolvido várias atividades de modelagem em sala de aula nos últimos anos. Além deste desenvolvimento muitas das nossas atividades foram fontes de dados para estudos que tratam do desenvolvimento de atividades de Modelagem e o envolvimento dos alunos $^{2}$. Diante do tema deste encontro apresentamos neste artigo uma síntese de algumas atividades que foram desenvolvidas com nossos alunos com o intuito de fomentar discussão sobre a contribuição que este desenvolvimento pode trazer para o futuro engenheiro.

\section{Modelagem matemática em engenharia}

Neste item abordamos temas trabalhados com alunos de engenharia. Apresentaremos o desenvolvimento de apenas uma atividade (Contaminação dupla de uma mistura com acetato de Etila), sendo que o desenvolvimento das outras pode ser encontrados em Ferruzzi (2003) e Ferruzzi (2011).

a) Tema Energia armazenada em um capacitor

Problema: Encontrar um modelo matemático que represente a energia acumulada em um capacitor.

\footnotetext{
${ }^{1}$ Ver Ferruzzi 2003.

${ }^{2}$ Resultados destas pesquisas podem ser encontrados em Ferruzzi (2011).
} 
Variáveis envolvidas: $U=$ tensão aplicada ao capacitor, medida em Volts $(V) ; t=$ tempo, medido em milissegundos (ms); $i=$ corrente, medida em amperes (A); $W=$ energia armazenada em um capacitor, medida em mileJoule (mJ); $p=$ potência, medida em Watts. (W) e $C=$ valor da capacitância, medida em microFaraday $(\mu \mathrm{F})$.

Modelos encontrados (com os dados da pesquisa) após determinação dos parâmetros:

$$
\begin{aligned}
& \mathrm{U}(\mathrm{t})=0,45 \operatorname{sen} \frac{2 \pi}{1,2} \mathrm{t} \\
& \mathrm{i}(\mathrm{t})=20 \mu \cdot 0,75 \cdot \pi \cos \left(\frac{\pi}{0,6} \cdot \mathrm{t}\right) \\
& \mathrm{p}(\mathrm{t})=10 \mu \cdot 0,3375 \pi \cdot \operatorname{sen}\left(\frac{2 \pi}{0,3} \mathrm{t}\right) \\
& W=\int_{0}^{\infty, 25} 20 \mu 0,3375 \pi \operatorname{sen}\left(\frac{\pi}{0,6} t\right) \cos \left(\frac{\pi}{0,6} t\right) d t \\
& W=\frac{20}{2} \cdot 0,45 \operatorname{sen}\left(\frac{\pi}{0,6} t\right)
\end{aligned}
$$

Modelo generalizado: $\mathrm{W}=\frac{\mathrm{C}}{2} \cdot \mathrm{U}(\mathrm{t})^{2}$

Conteúdos matemáticos abordados: funções periódicas, derivadas e integral definida de função real,cálculo da área sob uma curva.

b) Tema: Comportamento da temperatura em um forno elétrico

Problema: Determinar um modelo matemático que represente o comportamento da temperatura do interior de um forno elétrico em relação ao tempo.

Variáveis: $T=$ temperatura do forno elétrico, medida em graus Celsius, no instante $t, t=$ tempo, medido em minutos.

Modelo encontrado: $T(t)=303,1951265,42 . e^{0,1558 t}$

Conteúdos matemáticos abordados: Limites, intersecção de retas, função exponencial e o método de Ford-Walford.

c) Tema: Comportamento da corrente que flui em um circuito fechado em relação à tensão aplicada e ao resistor do equipamento.

Variáveis: $I=$ corrente medida em Ampères $(\mathrm{A})$ e $U=$ tensão aplicada, medida em Volts (V).

Circuitos fechados utilizados: ferro de passar roupas, chuveiro com a chave ligada para funcionar no inverno, chuveiro preparado para funcionar no verão e secador de cabelos.

Modelos encontrados com os dados estudados: Grupo1: $I(U)=0,32 U$; Grupo2: $I(U)=0,43 U$; Grupo3: $I(U)=0,011 U$; Grupo 4: $I(U)=0,07 U$.

Modelo generalizado $\mathrm{I}(\mathrm{U})=\frac{1}{\mathrm{R}} \mathrm{U}$.

Este modelo é conhecido na literatura como Lei de OHM. 
Conteúdos matemáticos abordados: Função do primeiro grau e Limites.

d) Tema: Análise do comportamento do pH da reação do Hidróxido de sódio com acetato de etila.

Variáveis: $A(t)$ : atividade do hidróxido de sódio, $t$ : tempo em minutos.

Modelo encontrado com os dados pesquisados: $A=0,0026063 \mathrm{e}^{-0,0225^{t}}$

Conteúdo matemático estudado: Equações Diferenciais

e) Tema: Estudo da capacidade térmica de um aquecedor solar construído na UTFPR, câmpus Londrina.

Problema:Estudar a capacidade térmica do aquecedor solar construído na UTFPR, câmpus Londrina - Pr.

Vários modelos foram encontrados e estudados, dentre eles temos a Temperatura da estufa em função do tempodT $T_{a} / d t=1 / 15000\left[735,6 \operatorname{sen}[(\pi / 12) t]-\sigma \cdot T^{4}+1538,75\right]$.

Conteúdo matemático estudado: Equações diferenciais, diferenças finitas

f) Tema: Estudo da contaminação de hidróxido de sódio em um recipiente de fluxo contínuo

Variáveis: $A(t)$ a quantidade de mols $\mathrm{NaOH}$ no instante $t$, $t$ : tempo em minutos

Dentre os modelos encontrados temos: A $=4,28 \quad 5,5122 \mathrm{e}$ 0,197(2t+1)

Conteúdos matemáticos estudados: métođ̨o de Ford-walford e Equações Diferenciais.

g) Tema Contaminação dupla de uma mistura com acetato de Etila

Problema: Estudar a variação da quantidade de acetato de Etila em um recipiente $(R)$ em que são adicionadas, em intervalos de tempo diferentes, duas misturas com concentrações diferentes de acetato de Etila $\left(c_{1}\right.$ e $\left.c_{2}\right)$. Durante o tempo em que são adicionadas as misturas existe um fluxo contínuo de saída da mistura homogênea.

Variáveis: $C(t)=$ concentração de acetato de etila (medida em $\mathrm{ml} / \mathrm{L}$ ) no instante $t ; t$ : tempo em minutos; $x(t)=$ quantidade de acetato de etila no instante $t$ ( medida em $\mathrm{ml}$ ).

Dados: Vazão de entrada e saída: 1,74 L/min; Concentração 1: $c_{1}=26,7 \mathrm{ml} / \mathrm{L}$ (concentração da mistura 1 que é adicionada nos 5 primeiros minutos); Concentração 2: $c_{2}=40 \mathrm{ml} / \mathrm{L}$ (concentração da mistura 2 é adicionada após os 5 primeiros minutos); Concentração 3: $c_{3}=$ $(x(t)) / V$ (concentração da mistura que está saindo em qualquer instante) e Volume do recipiente $(\mathrm{R}): \mathrm{V}=4,5 \mathrm{~L}$.

A tabela 1 apresenta os dados coletados relativos à concentração de acetato de Etila em relação ao tempo. 


\begin{tabular}{|c|c|}
\hline tempo(min) & $C(\mathrm{ml} / \mathrm{L})$ \\
\hline 0 & 0 \\
\hline 0,5 & 0,040365273 \\
\hline 1 & 0,069401803 \\
\hline 1,5 & 0,092050178 \\
\hline 2 & 0,118418249 \\
\hline 2,5 & 0,12781103 \\
\hline 3 & 0,134825836 \\
\hline 3,5 & 0,153506796 \\
\hline 4 & 0,160700574 \\
\hline 4,5 & 0,169520496 \\
\hline 5 & 0,190084525 \\
\hline 5,5 & 0,295947727 \\
\hline 6 & 0,329324913 \\
\hline 6,5 & 0,350061496 \\
\hline
\end{tabular}

Tabela 1 - Dados referentes à concentração de Acetato de Etila em relação ao tempo.

\section{Hipótese}

$\mathrm{H}_{1}$ : a taxa de variação da quantidade de acetato de etila em relação ao tempo é igual à diferença entre a quantidade que entra e a quantidade que sai;

\section{Modelo matemático associado à hipótese}

$$
\frac{d x}{d t}=M_{1}-M, \text { sendo } M_{1}=c_{1} \text {.vazão1 e } M=c_{3} \text {. vazão } 3 .
$$

Modelos matemáticos encontrados após a determinação dos parâmetros:

$$
\begin{aligned}
& L[x(t)]=\frac{46,46}{s(s+0,39)}+\frac{23,14 \mathrm{e}^{-5 s}}{\mathrm{~s}(\mathrm{~s}+0,39)} \\
& x(t)=\left\{\begin{array}{c}
119,13-119,13 e^{-0,39 t} \text { se } 0<t<5 \\
178,46-119,13 e^{-0,39 t}-59,33 e^{-0,39(t-5)} \text { set } \geq 5
\end{array} .\right.
\end{aligned}
$$

Conteúdos matemáticos envolvidos: Função Degrau Unitário e Transformada de Laplace. 
Após o estabelecimento da Equação Diferencial definida por duas sentenças os alunos iniciam os procedimentos para escrevê-la de forma compacta, utilizando a Função Degrau Unitário.

Em seguida transformam a função resultando em $L[23,14 \mu(t-5)]=\frac{23,14 \cdot \mathrm{e}^{-5 \mathrm{~s}}}{\mathrm{~s}}$.

Na sequência, isolam $L[x(t)]$, chegando à transformada

$L[x(t)]=\frac{46,46}{s(s+0,39)}+\frac{23,14 \mathrm{e}^{-5 s}}{\mathrm{~s}(\mathrm{~s}+0,39)}$.

Após o estabelecimento desta Equação diferencial os alunos utilizam a transformada inversa e encontram a função

$$
x(t)=\left\{\begin{array}{c}
119,13-119,13 e^{-0,39 t} \text { se } 0<t<5 \\
178,46-119,13 e^{-0,39 t}-59,33 e^{-0,39(t-5)} \text { set } \geq 5 .
\end{array} .\right.
$$

Após o término desta atividade os alunos apresentaram o modelo encontrado e fizeram algumas considerações sobre o mesmo. Nestas considerações os alunos se dizem satisfeitos por encontrar o modelo que representa a situação e apresentam algumas simulações de resultados, como por exemplo, concluem que, se considerassem apenas a entrada da primeira mistura, a concentração máxima que a mistura poderia alcançar seria $26,7 \mathrm{ml} / \mathrm{L}$, visto que esta é a concentração da mistura 1 , e deste modo, sabendo que o balde tem $4,5 \mathrm{~L}$ de volume, a quantidade máxima de ácido acético seria aproximadamente 120,15ml. Efetuando seus cálculos concluem que seria impossível chegar a este valor, fato este confirmado por seus conhecimentos sobre misturas. Deste modo, estimam uma quantidade máxima de $119 \mathrm{ml}$ e concluem que, se entrasse apenas a mistura 1, em aproximadamente 17,5 minutos a mistura estaria totalmente contaminada. Salientam ainda que, com a entrada da mistura dois, a velocidade de contaminação aumenta consideravelmente e que, em apenas 18 minutos aproximadamente, a mistura estará totalmente contaminada com uma quantidade igual à $178 \mathrm{ml}$.

Os alunos consideram ainda que esta atividade proporcionou o entendimento de como proceder para, por exemplo, estudar o nível de contaminação de um lago ou lagoa, em relação ao tempo, ou seja, com um modelo deste tipo poderiam monitorar a contaminação da água, tendo condições de estipular um máximo admissível e observar em que momento este máximo seria atingido, para então tomar as devidas providências, antes que o mesmo acontecesse. Na sequencia apresentamos uma conversa que a professora teve com os alunos ao término desta atividade e nela, podemos observar a satisfação dos alunos e algumas considerações que fazem a respeito da atividade. 
Prof: bom, esta foi nossa última atividade .. por enquanto né??/ [brincando com os alunos e os alunos rindo e concordando]. Gostaria de saber, o que vocês acharam de desenvolver estas atividades?

A6:.. nossa.. adorei...

A5:[junto com A6] adorei

A7: deixa as mulheres falarem primeiro...elas estão ansiosas.. [Em tom de brincadeira]

A5:: hã??? a sim!!!... se fosse outro homem [rindo]

A6:: se você começa falar você fala duas horas seguidas

Todos riem

Prof: fala você $A 5$

A5: então.. ela proporcionou uma coisa prática. eu vi assim... com a modelagem... tanto com o tema da concentração quanto da estufa... do aquecedor quer dizer.... [referindo-se a outra Atividade desenvolvida por este grupo]

Prof: o que você quer dizer com coisa prática?

A5: aplicar... aplicação...prá que que serve...eu to aprendendo prá que que serve...

Prof: por que?

A5: ah.. tem significado.. eu posso aplicar nisso... ou naquilo,.. Eu vi como isso aí sabe? Vi onde posso aplicar a matemática.

Prof: humhum

A5: eu gostei de ver onde aplicar o que aprendo em sala de aula, além de estudar outras coisas não ligadas diretamente à matemática... ter que pesquisar...

Prof: e o que você achou de ruim?

A5: ruim?

Prof: sim

A5: nada... é trabalhoso.. não que seja ruim...

Prof: o tempo... a demora??

A5: o duro que a gente não tinha.. é... não tinha tempo livre

Prof: se tivesse feito só em sala de aula... quer dizer... se tivesse ocupado só o período em que a gente estava na disciplina...

R. B. E. C. T., vol 6, núm. 1, jan-abr.2013 ISSN - 1982-873X

Artigo apresentado na II Jornada Brasileira do Grupo de Pesquisa Euro-Latino-Americano 
A5: hum [acompanhando a professora]

Prof: se fosse apenas no período da disciplina, teria sido melhor?

A7: como é que é?? Se tivesse feito esse aqui em sala de aula?

Prof: é.. teria sido melhor?

A7: não ia dar tempo né? Não ia dar tempo...

A6: ia ficar incompleto.. tinha muita coisa prá aprender para fazer...

Prof: era muito ruim vir fora de horário? Prá fazer o trabalho?

A7: para mim, particularmente não... eu gostava de fazer a modelagem

A5: se a gente tivesse mais tempo... mas a gente sempre acabava dando um jeito, porque queria fazer o trabalho, porque queria ver o resultado.

A6:Tipo assim: quando a gente fez matemática dois foi suficiente (os trabalhos desenvolvidos) e agora foi legal porque a gente conseguiu aprofundar mais.

A5: humhum [concordandocom A6]....e se a gente precisar vai lembrar

A7: transformada de laplace não é difícil... ela só é várias continhas que tem que ir encaixando...tem que fazer as integrais impróprias e depois junta tudo... depois faz a inversa...acho que poderíamos ter modelagem como uma matéria optativa... modelagens... modelagens ambientais

A5: naquele outro trabalho a gente usou o curve...

A6: até Java a gente usou.... [rindo]

A5: usamos tudo que podia ...[rindo]

A7: igual A5 falou: quando a gente precisar vai saber pelo menos por onde começar... Esse negócio de contaminação, é um problema que sempre vai aparecer, tratar de um efluente, às vezes em uma indústria... que você vai tá mexendo com resíduo. Aí a gente pode modelar de acordo com o tempo, ou de acordo com a dosagem...Por exemplo, se tá contaminando um determinado local... a gente estipula o máximo... quer dizer, já é estipulado né? O quanto poderia estar contaminada esta água.... aí a gente tem o modelo e com ele a gente pode investigar quando vai chegar nesse máximo e fazer alguma coisa antes disso acontecer. Neste caso a gente mexeu com ácido acético e água, mas A6 mesmo tá mexendo com modelagens atmosféricas, tá trabalhando com componentes atmosféricos e ar ...

A5: a gente simulou em laboratório...com os baldes, mas ficou bonito.. deu certinho... o importante é saber como fazer... como encontrar o modelo... a gente 
teve que aprender coisas que não sabia. E outras coisas que a gente sabia mas não sabia para que servia.

A6: interessante o que a gente pode fazer com os dados né prof?

Prof: como assim?

A6: ah.. se a gente quisesse a gente poderia modelar por uma função exponencial, mas a gente fez como uma função linear porque o prof falou que a calibração era linear. (referindo-se a uma curva de calibração que realizaram e a um professor de outra disciplina)

A7: não é que a gente tá mentindo com os dados, estamos olhando diferente, olhando para o que queremos.. é assim que fazem as pesquisas políticas. Um partido vai lá e fala uma coisa, o outro fala outra. Não é que estão mentindo nos dados, estão olhando diferente, calculando diferente.

Prof: é muito importante vocês entenderem isso. A gente tá em uma área exata. no caso de vocês, engenharia, mas tem que ter essa visão crítica, olhar as coisas com cuidado, e saber aplicar a matemática

A7: a gente pode fazer outra... onde entra água limpa também... aí vai demorar mais para ficar totalmente contaminado... se é que vai ficar totalmente contaminado né? Acho que não vai....

Prof: mas essa aí é outra atividade...vamos deixar para depois ok?

\section{Contribuição para o ensino de Matemática na Engenharia}

Descrevemos neste ítem um pouco da nossa análise no desenvolvimento destas atividades para a aprendizagem dos alunos de engenharia, levando em consideração o desenvolvimento de aspectos sociais, do reconhecimento do papel da matemática na sociedade, da utilização de conceitos matemáticos, do desenvolvimento de alguns aspectos cognitivos e a eficiência da utilização da modelagem para o processo de aprendizagem da matemática.

A análise aqui descrita está fundamentada em informações obtidas por diferentes instrumentos:

i) observações diretas do comportamento dos alunos durante todo o processo de desenvolvimento das atividades. Nestas observações procurou-se identificar alguns comportamentos dos alunos e em seguida foram anotados em diários de campo. As anotações auxiliaram a observação dos aspectos sociais tais como: interação entre os alunos, cooperação, pensamento crítico e responsabilidade. Ainda auxiliaram na análise quanto ao desenvolvimento de alguns aspectos cognitivos, como a compreensão de situações extra-matemáticas, elaboração 
de estratégias próprias de resolução de problemas e aplicação de conhecimentos em situações que necessitem dos conceitos matemáticos.

ii) análise do trabalho escrito: As atividades desenvolvidas pelos alunos foram apresentada ao professor em forma de trabalho escrito. A ficha de observação da atividade escrita permitiu identificar os seguintes aspectos: estética, criatividade, capacidade de expressão escrita, desenvolvimento e domínio do conteúdo em questão, resolução correta do problema em estudo, organização das idéias e a capacidade de síntese do trabalho.

iii) apresentação oral da atividade: Na apresentação oral do trabalho foi possível observar a aprendizagem em relação aos conteúdos matemáticos envolvidos, bem como a clareza das idéias e a criatividade de apresentação. Os itens observados nesta apresentação foram a clareza das idéias e conceitos, organização das idéias, domínio do conteúdo, criatividade e capacidade de expressão oral. Nesta atividade os alunos que assistiam as apresentações avaliaram as equipes e deram suas notas para cada elemento do grupo individualmente e para a equipe como um todo. Deste modo, estas atividades também proporcionaram o desenvolvimento da criticidade nos alunos, os quais se mostraram críticos em suas avaliações, justificando suas observações e notas atribuídas aos colegas. Assim, de posse destas informações foi possível analisar alguns aspectos sociais e cognitivos bem como a aquisição dos conteúdos matemáticos.

iv) Aplicação de um questionário final e entrevistas gravadas: As informações obtidas neste item proporcionaram a observação de alguns aspectos quanto ao reconhecimento do papel da matemática na sociedade, bem como a importância dos conceitos matemáticos para o bom desempenho de sua vida profissional e acadêmica, além do incentivo à pesquisa, resolução de problemas cotidianos com o auxilio da matemática e a constatação por parte dos entrevistados da compreensão dos conteúdos matemáticos.

Algumas atividades foram filmadas e analisadas posteriormente. As conclusões que apresentamos neste item têm como base comentários dos alunos e os instrumentos citados.

\section{a) Quanto aos aspectos sociais}

No transcurso da atividade observou-se que a interação entre os alunos, a cooperação, a criticidade e a responsabilidade foram sendo desenvolvidas. $O$ diálogo entre professor e alunos era constante. Os alunos questionavam mais, pareciam mais a vontade em relação à discussão de suas idéias, além de não apresentaram receio em expor e argumentar a respeito de suas conclusões. Algumas falas dos alunos identificaram este fato, com por exemplo: "Os alunos se soltaram muito nas nossas aulas, isso foi bom... A Matemática fica ruim quando o professor se fecha e os alunos também... Nestas aulas os alunos se soltaram bastante..."

Em falas dos alunos observou-se a aprovação quanto ao trabalho em equipe "Houve momentos de distração...momentos de trabalhos...Todos da sala souberam diferenciar esses momentos...Tudo que tinha que ser feito,foi feito..." "A atividade em equipe ajuda muito,porque 
tendo alguém para discutir fica mais fácil chegar à compreensão...Nestas discussões, sempre tem uma opinião diferente...sempre tem um que está certo, então se a gente estava errado e o outro já corrigia na hora, chegávamos à conclusão de quem estava certo, quem estava errado..."

\section{b)Quanto ao reconhecimento do papel da Matemática na sociedade}

Algumas falas dos alunos asseguram que os mesmos entenderam o significado da importância da matemática para sua vida acadêmica e profissional:

"... com as atividades fora da sala de aula a gente pode encontrar operações usadas aqui dentro que a gente trabalha no cotidiano, tá sempre vendo, mas nunca presta atenção no que está acontecendo, mas sempre tá ali acontecendo... e com este trabalho deu para gente encontrar... ficou mais fácil compreender porque usa e quando usa a matemática... Achei muito interessante o trabalho", "Achei que esta atividade foi uma das melhores coisas que teve, pois coloca o aluno em situações da sua área de atuação", " nas aulas foram aplicadas atividades que considero extremamente importantes para o desenvolvimento acadêmico e profissional", "Onde faço estágio, para programar os equipamentos precisamos da matemática, integrais, derivadas... então, se não tiver uma boa Matemática a pessoa vai ficar com dificuldades...",

\section{c) Desenvolvimento e utilização de conceitos matemáticos}

Uma análise do desenvolvimento dos conceitos matemáticos no decorrer das disciplinasem que foram desenvolvidas estas atividades foi realizada por meio de provas, da observação sistemática realizada durante o desenvolvimento das atividades de resolução de problemas e das atividades de modelagem realizadas na sala de aula, bem como por meio da apresentação oral dos alunos. Analisando as respostas obtidas no questionário, observa-se que os alunos consideram que os conteúdos ministrados foram compreendidos de forma satisfatória,

"Eu já tinha feito esta disciplina antes e não tinha aprendido..agora aprendi..." " neste semestre, como estou fazendo dependência, percebi que dentre todas as vezes que fiz essa matéria, neste semestre está bem mais interessante, particularmente confesso que estou compreendendo mais a matéria devido ao método utilizado", "Meu aprendizado foi muito maior agora...O método deve continuar... seria bem mais fácil...O ideal é sempre trabalhar com o cotidiano, na aplicação do cotidiano, porque aí a gente pode saber onde está trabalhando e não ficar apenas com a parte teórica, porque muitas vezes a gente aprende a teoria mas não sabe onde aplicar...", "Desta vez foi mais fácil a compreensão porque primeiramente trabalhava-se com os problemas depois víamos o conteúdo para resolve-lo...assim ficou mais fácil para aprender, porque a gente vendo na prática ficou mais fácil a gente aprender a teoria..."

R. B. E. C. T., vol 6, núm. 1, jan-abr.2013 ISSN - 1982-873X

Artigo apresentado na II Jornada Brasileira do Grupo de Pesquisa Euro-Latino-Americano 


\section{d) Quanto aos aspectos cognitivos}

As informações coletadas durante o desenvolvimento das atividades por meio dos registros em diário de campo, das entrevistas gravadas e das filmagens oportunizaram observar o desenvolvimento da habilidade de elaborar estratégias de resolução. Em geral, os indivíduos do grupo sugeriam um modo de solução para o problema proposto e após discussões realizadas, concordava-se com uma ou outra estratégia para solucionar o problema. Por outro lado, observou-se também, que em algumas situações dois ou três elementos do grupo solucionaram o problema de maneiras distintas. No transcorrer da disciplina verificou-se ainda, que os alunos adquiriram compreensão sobre as aplicações dos conteúdos matemáticos. $\mathrm{O}$ discurso dos alunos modificou-se significativamente no transcorrer da disciplina. Visualizaram a aplicabilidade como também aprovaram o uso destas em sala de aula, como se pode verificar em alguns comentários:

"É difícil aprender quando a gente está só vendo as coisas no quadro... a gente vê e não sabe onde vai usar... Vendo na prática a gente vai descobrindo onde ela se encontra" "Foi muito interessante o trabalho por causa da compreensão dos conteúdos. Se a gente fica só com aulas no quadro a gente não enxerga a aplicação... o que aconteceu com os problemas que resolvemos...".

\section{Para finalizar}

A análise descrita no item anterior ilustra como a Modelagem em sala de aula possibilita a integração entre alguns conteúdos curriculares e a análise e resolução de problemas específicos da área de atuação do estudante.

A escolha do tema, a coleta de informações e dados realizada pelos alunos, fez com que cada um se sentisse responsável pela resolução do problema e sentiram-se entusiasmados com a possibilidade de estarem participando ativamente da solução do problema proposto.

De modo geral, observamos que as atividades desenvolvidas proporcionaram o desenvolvimento de habilidades e competências imprescindíveis para a formação dos alunos, ultrapassando elementos puramente técnicos do aprendizado. As apresentações orais e escritas dos trabalhos propiciaram o desenvolvimento de atitudes positivas para o crescimento pessoal e profissional, tais como a organização de idéias, clareza na apresentação, criatividade, capacidade de expressão, capacidade de comunicação oral.

Um dos objetivos do desenvolvimento de atividades de Modelagem em sala de aula foi despertar o interesse em adquirir novos conhecimentos. Observamos que este interesse ocorreu, visto que a necessidade de solucionar o "seu" problema fez com que estes alunos empenhassem esforços para compreender os conceitos relacionados para solucioná-lo. Estes esforços levou-os a pesquisas extra-curriculares bem como a busca de profissionais da área e busca na literatura. 
Assim, consideramos que mesmo em um curso regular, com limitações de tempo e conteúdos do programa, é possível desenvolver atividades de Modelagem Matemática e proporcionar o desenvolvimento de conteúdos matemáticos, bem como atitudes de investigação, resolução de problemas e habilidades sociais do futuro engenheiro.

As atividades apresentadas neste artigo têm o objetivo de mostrar que o uso da Modelagem Matemática em sala de aula pode contribuir com a educação matemática e geral do estudante de engenharia. Salientamos que as considerações e conclusões aqui apresentadas dizem respeito a um grupo específico de alunos. Outras pesquisas devem ser feitas para corroborar ou não nossas conclusões. 


\section{Agradecimentos}

Agradecemos à Allan Marcel Nishioka (in memoriam), Ana Carolina Pierotti Jacobs, Fernanda Bezerra Mangili, Livia Deliberador Francescon, Marcela Arfelli Silva, Mateus Mesquita De Paula Alves Nunes, Matheus Henrique Da Silva, Michel luri Caetano, Monica Hirata Bertachi, Nariane Marselhe Ribeiro Bernardo, Noelle Santos Salsa, Paula Fernanda Almeida Goncalves, Rafael Coelho Ciciliato e Vitor Manoel Nogueira Alvares, e ainda aos alunos da turma M 41/20021, da disciplina de Circuitos e Medidas do Curso Superior de Tecnologia em Eletrotécnica, nossos alunos e autores destes trabalhos de Modelagem Matemática. 


\section{Referências}

Almeida, L. M. W.eFerruzzi, E. C. Uma aproximação socioepistemológica para a modelagem matemática. Alexandria, v. 2, p. 117-134, 2009.

Bathelt, R. E. e Ceolin, G. M.Transformações Educacionais na Virada do século XXI: Implicações para o ensino da Matemática. Disponível na página da web: http:// www.ufsm.br/adeonline/regina.html. acessada em 23-10-2001.

Biembengut, M. S. Qualidade de Ensino de Matemática na Engenharia: uma proposta metodológica e curricular. Florianópolis: UFSC, 1997. Tese de Doutorado, Curso de Pós-Graduação em Engenharia de Produção e Sistemas, 1997.

Blum, W. Applications and modelling in Mathematics teaching - A review of arguments and instructional aspects. In: M. Niss et al (eds), Teaching of mathematical modelling and applications.Chichester: Ellis HorwoodLmited, 1991.

Coll, C. Significado e Sentido na Aprendizagem Escolar. Reflexões em Torno do Conceito de Aprendizagem Significativa. In: Coll Salvador, C. Aprendizagem escolar e construção do conhecimento. Porto Alegre: Artes Médicas, 1994.

Ferruzzi, E. C. A Modelagem Matemática como estratégia de ensino e aprendizagem do Cálculo Diferencial e Integral nos Cursos Superiores de Tecnologia. Dissertação de Mestrado. UFSC -SC. 2003.

Ferruzzi, E.C. Interações discursivas e aprendizagem em Modelagem Matemática. 2011. Tese. Doutorado em ensino de ciências e Educação Matemática. Londrina, 2011.

Pinheiro, N. A. M. e Moretti ,M. T. Conhecimento matemático reflexivo no ensino de cálculo diferencial e integral: uma contribuição para as discussões sobre ciência,tecnologia e sociedade. Anais do II SIPEM - simpósio Internacional de pesquisa e Educação matemática. Santos, 2003.

Vallim, M.B.R.; Farines, . e Cury, J.E.R.Uma estrutura curricular para um curso de engenharia de controle e automação. In: Congresso Brasileiro de Automática, 2006. Anais eletrônicos do XVI CBA. Salvador. BA. 2006. 1 CD.

R. B. E. C. T., vol 6, núm. 1, jan-abr.2013 ISSN - 1982-873X 
Elaine Cristina Ferruzzi: professora pesquisadora da Universidade Tecnológica Federal do Paraná, cämpus Londrina.Doutora em Ensino de Ciências e Educação Matemática pela Universidade Estadual de Londrina. Mestrado em Engenharia de Produção pela Universidade Federal de Santa Catarina (2003) e graduação em Matemática pela Universidade Estadual de Londrina (1989). Atualmente é professora da Universidade Tecnológica Federal do Paraná, onde, além das atividades docentes foi coordenadora do I e II Curso de especialização em Instrumentalização para o ensino de Matemática e Coordenadora da I Turma do Programa Especial de Formação pedagógica da UTFPR, campus Londrina. Tem experiência na área de Matemática, com ênfase em Modelagem Matemática, atuando principalmente nos seguintes temas: modelagem matemática, educação matemática, investigação matemática e Matemática para graduação.elaineferruzzi@utfpr.edu.br

Lourdes Maria Werle de Almeida: professora pesquisadora do Programa de Pós-graduação em Ensino de Ciências e Educação Matemática da Universidade Estadual de Londrina. Professora da Universidade Estadual de Londrina desde 1985, atualmente na categoria de professor associado, atua no curso de graduação em Matemática e no Programa de Pós-Graduação em Ensino de Ciências e Educação Matemática, programa no qual já ocupou a função de coordenadora e de vice-coordenadora. Tem experiência na área de Matemática, com ênfase em Educação Matemática, atuando principalmente nos seguintes temas: modelagem matemática, formação de professores de matemática sendo coordenadora do GRUPEMAT Grupo de Pesquisas sobre Modelagem e Educação Matemática. Como membro da Sociedade Brasileira de Educação Matemática atualmente é coordenadora do GT de Modelagem Matemática da SBEM nacional. Tem projetos aprovados pela Fundação Araucária e pela CAPES. Atualmente é coordenadora institucional do projeto do Observatório da Educação na UEL. Lourdes@uel.br 